\title{
Study of cardiac rhythm in healthy newborn infants
}

\author{
D P SOUTHALL, JEAN RICHARDS, PRUDENCE MITCHELL, D J BROWN, \\ P G B JOHNSTON, E A SHINEBOURNE
}

From the Department of Paediatrics, Brompton Hospital and Cardiothoracic Institute, London

SUMMARY Twenty-four-hour electrocardiograms were recorded in the first 10 days of life on 134 healthy full-term infants with birthweights greater than $2.5 \mathrm{~kg}$. The highest heart rate a minute, measured over nine beats, was $175 \pm 19$ (SD). The lowest rates, measured over three, five, and nine beats were $82 \pm 12,87 \pm 12$, and $93 \pm 12$, respectively. At their lowest rates 109 infants had sinus bradycardia and 25 had junctional escape rhythms. Thirty-three infants showed changes in $P$ wave configuration with or without pronounced variation in PR interval. Atrial premature beats were present in 19 infants but only one had more than 12 per hour.

In a randomly selected subgroup of 71 infants sinus pauses were found in $51(72 \%)$. Five (7\%) had electrocardiographic patterns and rhythm disturbances that could not be differentiated from those previously described as complete sinuatrial exit block or sinus arrest, eight $(11 \%)$ had patterns indistinguisable from 2:1 sinuatrial block, and $23(32 \%)$ had patterns indistinguishable from sinuatrial Wenckebach block.

This study shows that normal infants have variations in heart rate and rhythm hitherto considered to be abnormal.

The range of heart rate and nature of heart rhythms are poorly documented in normal healthy infants. Twenty-four-hour recordings of the electrocardiogram provide an accurate means of measuring heart rate and rhythm over long periods. The technique does not seriously interfere with normal behaviour and therefore documentation of changes in rhythm and rate is possible during activities such as sleeping, feeding, or crying. This report describes the results of single 24-hour recordings of the electrocardiogram on 134 healthy full-term neonates who weighed over $2.5 \mathrm{~kg}$ at birth.

\section{Patients and methods}

Studies were made between birth and 10 days of age (the normal period of postnatal hospitalisation in this area) on 134 randomly selected infants born in West Dorset between January 1977 and June 1978. They were all healthy and recordings were performed in the maternity ward before discharge home. All infants studied had normal standard 12 lead electrocardiograms with a 10-second rhythm strip. They were studied under standard maternity ward environmental conditions and were fed and handled normally by their mothers during the recording period.

Received for publication 5 July 1979
The recordings were made onto a Medilog cassette recorder ${ }^{\star}$ and the tapes were analysed for the presence of arrhythmias using a playback system $^{\star}$ and arrhythmia detector*, by a trained technician. The Medilog recorder and analyser incorporated a synclock mechanism which, by providing and processing a reference time signal, ensured that possible variations in tape speed did not produce artefactual rhythm or rate disorders. Mothers were encouraged to handle their babies in the normal way while recordings were taken.

Heart rates during activity and rest were measured by a histogram module in the analyser*. Histograms of the distribution of different heart rates (as obtained by continuous measurement of all intervals) were made on 79 babies during approximately two hours each of activity and rest.

The maximum heart rates, measured by direct electrocardiographic analysis, over nine consecutive beats were recorded. The minimum rates found over three, five, and nine consecutive beats were also measured in this way and the heart rhythm at this time (whether sinus or junctional) was noted.

The number of premature beats over 24 hours was measured by counting them in four different, randomly selected, hours of recording and computing the total.

* Oxford Instrument Company. 
Values for maximum and minimum heart rates were analysed and compared for ages 1 to 3 days and ages 4 to 10 days.

Seventy-one randomly selected recordings were analysed to determine if PP intervals were present which exceeded the previous PP interval by more than 50 per cent. If the QRS complex by which this

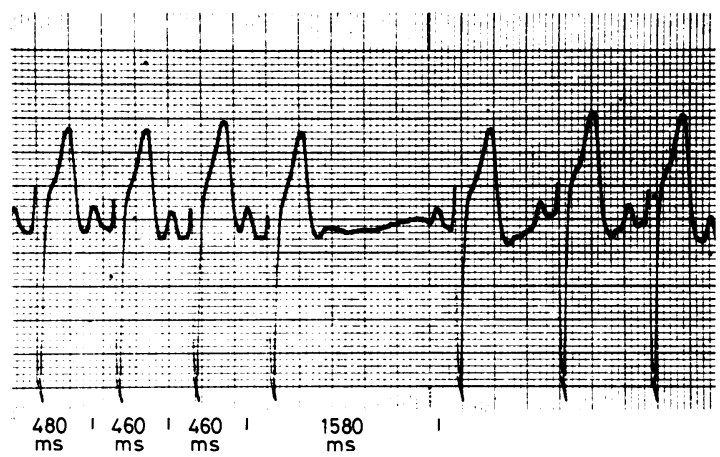

Fig. 1 Extract from 24-hour electrocardiogram showing sudden lengthening of PP interval by more than 110 per cent of previous PP interval. This electrocardiographic pattern and rhythm disturbance cannot be distinguished from complete sinuatrial exit block or sinus arrest.

interval was terminated was not preceded by a $P$ wave the $P Q$ interval was measured. When the PP or PQ interval exceeded the previous PP interval by more than 110 per cent this was classed as a pattern indistinguishable from complete sinuatrial block or sinus arrest (Fig. 1); intervals of between 90 and 110 per cent were classed as patterns of 2:1 sinuatrial block (Fig. 2) and intervals between 50 and 90 per cent were classed as sinus pauses (Fig. 3). This latter group was also assessed with respect to the pattern of PP intervals (a minimum of three) by which they were preceded.

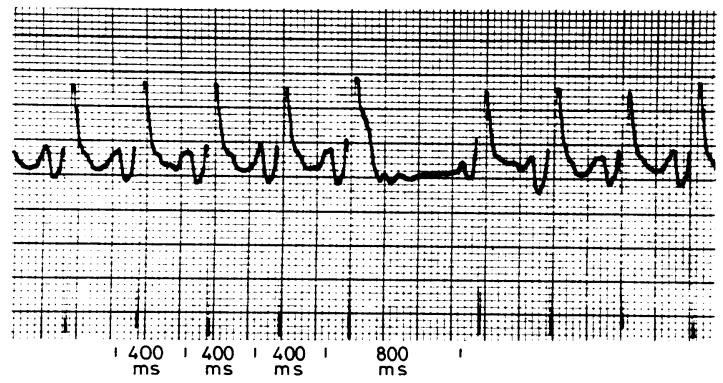

Fig. 2 Extract from 24-hour electrocardiogram showing sudden lengthening of PP interval by between 90 and 110 per cent of previous PP interval. This electrocardiographic pattern and rhythm disturbance cannot be distinguished from $2: 1$ sinuatrial block.
(1) Progressive increase in PP intervals.

(2) Regular PP intervals.

(3) Irregular PP intervals.

(4) A progressive decrease in PP intervals, that is a sinuatrial Wenckebach block pattern (Fig. 3c and 4$).^{1}$

To differentiate sinuatrial Wenckebach block patterns from those of sinus arrhythmias we used the calculations of Schamroth and Dove ${ }^{1}$ (see legend to Fig. 4) and also plotted the preceding PP intervals against their succeeding $P P$ intervals (Fig. 5). The percentages used in our calculations were chosen empirically to try and match the labels and character of sinuatrial block pattern used by previous workers.

\section{Results}

All infants were predominantly in sinus rhythm and showed a minimal, continuous irregularity of rate previously termed phasic variation. ${ }^{2}$

The distribution of heart rates (derived from $R R$ intervals) at rest and during activity measured by the histogram module in the analyser showed a maximum heart rate of 250 /minute and a minimum rate of $85 /$ minute. Direct electrocardiographic analysis of these higher and lower heart rates showed them to be spuriously high because of the interpretation of movement artefact and large $T$ waves as $R$ waves.

The histogram of the highest rate achieved over 24 hours measured by direct electrocardiographic analysis over nine beats did not differ significantly from a curve of normal distribution ${ }^{\star}$ with a mean rate of $175 \pm 19$ (SD). The highest heart rate found was $225 /$ minute. The histograms of the lowest rates measured by direct electrocardiographic analysis over three, five, and nine beats duration over 24 hours also did not differ from a normal distribution. ${ }^{\star}$ The mean lowest heart rate when measured over three beats was 82 /minute, over five beats was $87 /$ minute, and over nine beats was $93 /$ minute. The standard deviation in each case was 12 .

Of 134 infants, 109 at their lowest heart rates had sinus bradycardia and 25 had junctional escape rhythms. All infants showed sudden short episodes of bradycardia (Fig. 6).

The three infants with the lowest heart rates are described in more detail. One aged 8 days had an episode of bradycardia of 10 beats duration when the rate fell to $42 /$ minute. This began with two atrial premature beats, was followed by a sinus pause of 1.8 seconds, and continued with a slow junctional escape rhythm (Fig. 7). Four other episodes of bradycardia occurred during the $\star^{\text {COnfirmed by Kolomogorov-Smirnov test. }}{ }^{3}$ 
recording. The second infant aged 2 days showed an episode of 14 beats duration where the rate fell to $59 /$ minute. His only sib had previously died from the sudden infant death syndrome. The third infant was 4 hours old when the 24-hour recording was started. Subsequent analysis showed seven episodes of bradycardia of between 59 and 63/minute and of between 12 and 18 beats duration. The first three episodes coincided with cyanotic attacks, observed by the nursing staff and treated by stimulation and oronasal suction. No cause was found for these attacks. Though there were four further episodes of bradycardia during the night no cyanotic attacks were detected.
Fig. 3 Four extracts from 24-hour electrocardiograms on different infants showing sinus pauses. In each case there is sudden lengthening of $P P$ or $P Q$ intervals exceeding previous $P P$ intervals by 50 to 90 per cent. In (A) preceding PP intervals are regular; in (B) they are irregular, and in (D) they are increasing before the pause. In (C) there is progressive decrease in $P P$ intervals before the pause and this electrocardiographic pattern cannot be distinguished from sinuatrial Wenckebach block.
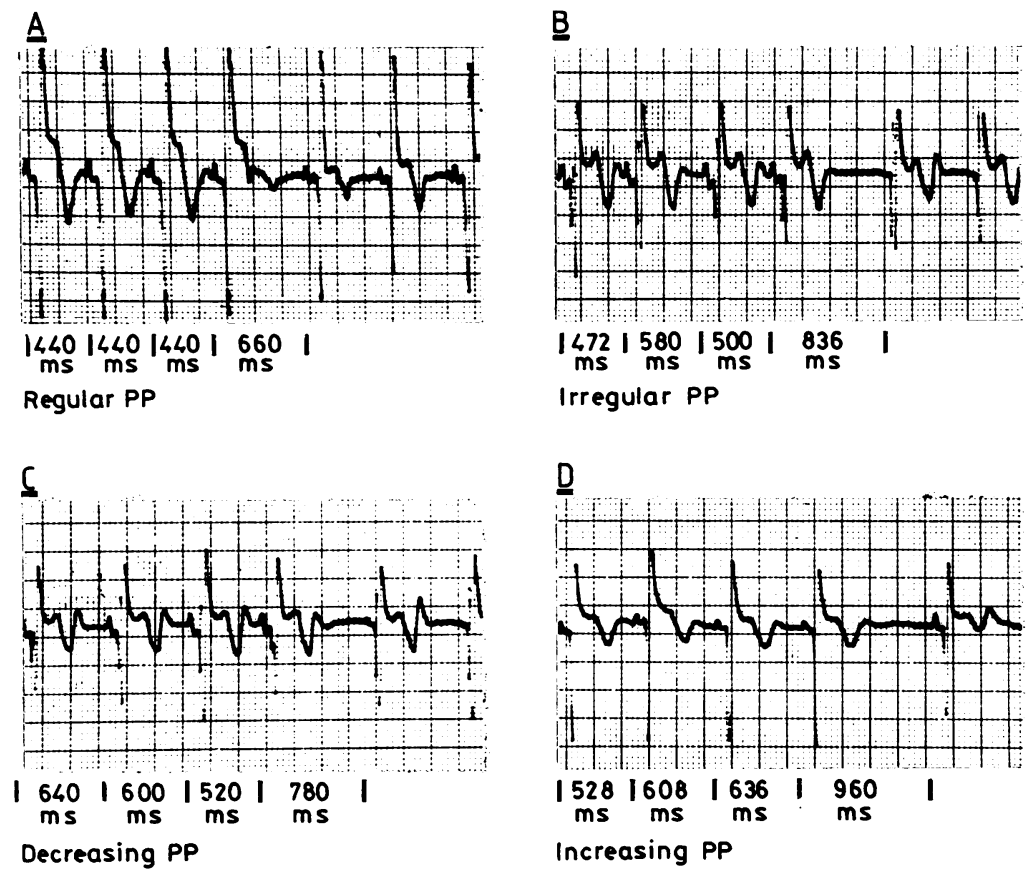

( $S$ A Wenckebach)

$P 1-P 2$ increment $=610-498=112$

$P 2-P 3$ increment $=520-498=22$

$$
\text { Total increment }=134
$$

$860+134=994$ which is approximately twice sinus cycle of 498.

Sinus extrasystole before pause is unlikely because pause exceeds.sinus cycle by $362 \mathrm{~ms}$. 
Table 1 Analysis of extrasystoles from single 24-hour electrocardiograph recordings on 134 infants

\begin{tabular}{lc}
\hline No. of extrasystoles in 24 hours & No. of infants \\
\hline 1 to 12 & 12 \\
12 to 24 & 1 \\
24 to 48 & 2 \\
96 to 120 & 2 \\
144 to 168 & 1 \\
480 to 600 & 1 \\
\hline
\end{tabular}

Changes in $\mathrm{P}$ wave configuration and $\mathrm{PR}$ interval variation occurred in $33(25 \%)$ infants (Fig. 8).

Nineteen infants $(14 \%)$ had atrial premature beats but only one had more than 12 per hour (Table 1).

There was no significant difference between the two age groups, 1 to 3 days and 4 to 10 days, for measurements of maximum and minimum heart rates (Table 2).

Of the subgroup of 71 infants, five $(7 \%)$ had electrocardiographic patterns, ie sinus pauses, that could not be differentiated from those described in all the other articles studied as complete sinuatrial exit block or sinus arrest (Fig. 1). Eight infants $(11 \%)$ had sinus pauses indistinguishable from 2:1 sinuatrial block (Fig. 2).

The longest interval between an escape beat and the previous sinus beat was 1.8 seconds (Fig. 6).

Sinus pauses representing increases in PP intervals of 50 to 90 per cent were found in 51 subjects $(72 \%)$ with preceding PP interval patterns as follows (Fig. 3). (1) Progressive increase 23 subjects $(32 \%)$; (2) regular PP intervals 14 subjects $(20 \%)$; (3) irregular PP intervals 35 subjects $(50 \%)$; and (4) progressive decrease (sinuatrial Wenckebach pattern) 23 subjects (32\%) (Fig. 3c and 4). The calculations of sinus cycle increments (Fig. 4) and graphs of succeeding PP interval measurements
(Fig. 5) supported the presence of Wenckebach conduction rather than sinus arrhythmia in all 23 subjects.

Some subjects showed more than one pattern.

\section{Discussion}

The range of heart rates found in these healthy neonates is wider than previously reported on standard electrocardiograms. ${ }^{4}$ The mean lowest rate measured by direct electrocardiographic analysis over nine beats was $83 /$ minute, with a standard deviation of 12 . Heart rates as low as $60 /$ minute for short periods of time are therefore to be expected in the normal neonatal population. Though 25 per cent of infants at their lowest rates had short episodes of junctional escape rhythm, prolonged periods of junctional rhythm with retrograde $P$ wave activity were not found in our study. Episodes of sudden bradycardia are a distinct feature of the cardiac rhythm at this age and have previously been reported in association with sudden deep breaths, hiccoughs, bowel movements, and vomiting. ${ }^{2} 6 \mathrm{We}$ are at present evaluating the relation of apnoea and other physiological functions to these episodes. ${ }^{7}$

Electrocardiographic patterns that we could not differentiate, without invasive electrophysiological tests, from those described in previous studies as complete, 2:1, Wenckebach sinuatrial block, or sinus arrest were found in 50 per cent of infants studied. They were also found in our recently completed investigation of 24-hour electrocardiograms on 92 randomly selected healthy children aged 7 to 11 years. $^{8}$ These electrocardiographic patterns have often been interpreted as disorders of sinus node function and clinical events such as faints, 'funny turns', or blackouts ascribed to this cause when these electrocardiographic patterns are

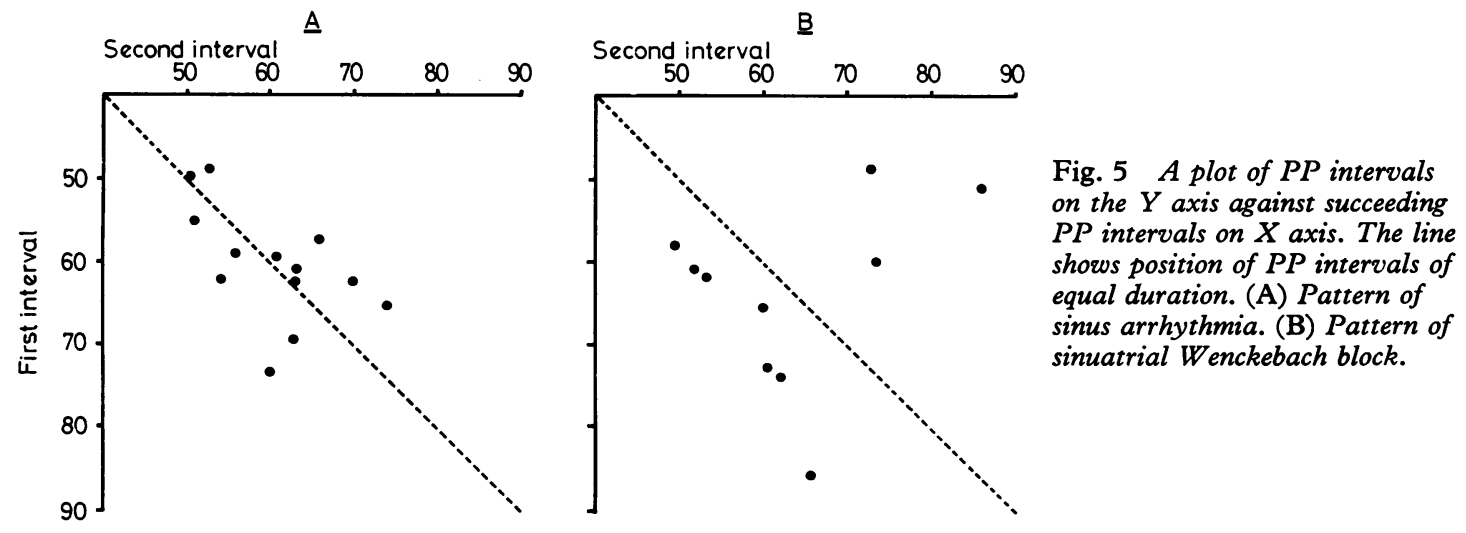


Fig. 6 24-hour electrocardiogram showing sudden short-lived episode of bradycardia at $72 / \mathrm{min}$ (as measured over five beats) with a junctional escape rhythm.

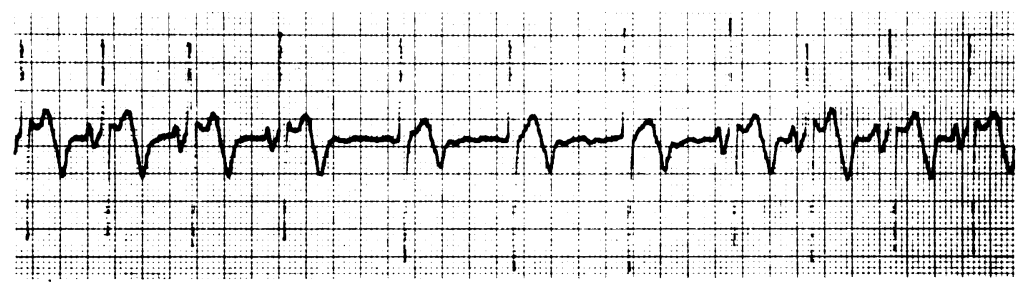

Fig. 7 24-hour electrocardiogram showing sudden bradycardia of approximately 12 seconds duration where heart rate falls to $42 / \mathrm{min}$ (as measured over nine beats). Bradycardia begins with two atrial premature beats and is followed by sinus pause and slow junctional escape rhythm. First escape beat is preceded by $P$ wave but is probably junctional in origin. This episode of bradycardia includes an asystolic pause of 1.8 seconds.
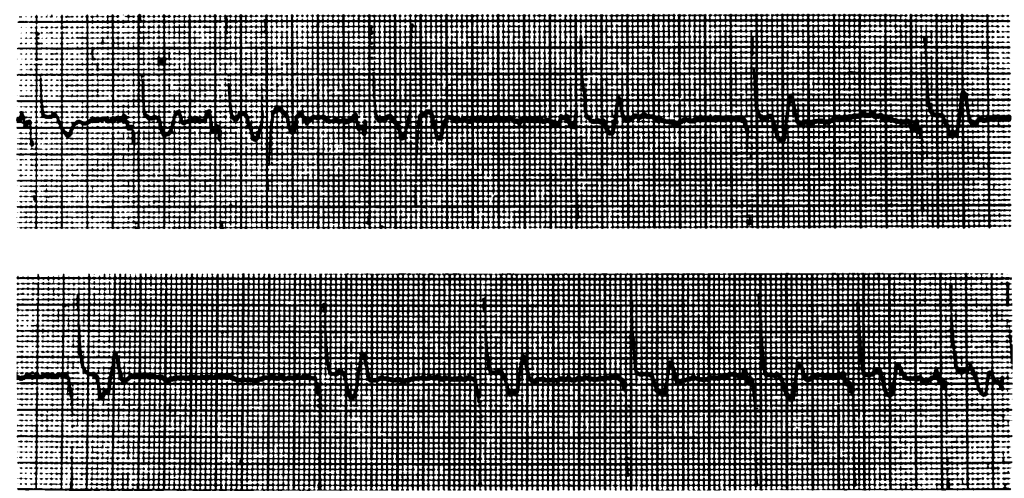

Fig. 8 24-hour electrocardiogram showing variation in $P$ wave configuration and duration of $P R$ interval, without changes in heart rate.

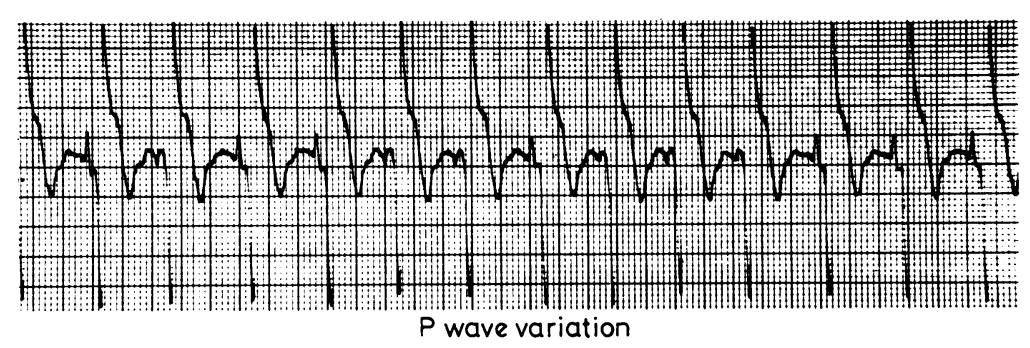

found on standard or 24-hour electrocardiograms. ${ }^{9} 10$ Moreover, the management of the 'tachycardiabradycardia' syndrome is often said to be complicated by inappropriate bradycardias when suppressant therapy is given for the tachycardia. ${ }^{9}$ The degree and patterns of bradycardia regarded as inappropriate must also take normal data into consideration and not lead to the unnecessary withholding of therapy.

In the assessment of surgical procedures for congenital heart disease ${ }^{11-13}$ intermittent junctional escape rhythms and electrocardiographic patterns similar to those described above have been, in all cases, interpreted as disorders of sinus node function and assumed to be acquired arrhythmias. This supposition is probably incorrect.

As electrocardiographic patterns indistinguishable from sinuatrial block and junctional rhythm are now known to occur frequently in healthy neonates and children, other criteria, on standard or 24-hour electrocardiograms, are necessary to determine if there is an abnormality of sinus node function. One possibility is to measure the time taken for an escape rhythm to be initiated after a sinus pause. The longest escape interval found in healthy neonates studied here was 1.8 seconds. In a recent report of an example of the sick sinus syndrome in an infant with sinuatrial and atrioventricular conduction disturbance, proven by electrophysiological studies, episodes of asystole exceeding four seconds were described. ${ }^{14}$

In our opinion all the premature beats found in this investigation were supraventricular. To arrive at this conclusion we examined the width of the QRS complex and the length of the compensatory pause, and looked for preceding $\mathbf{P}$ waves. We have already reported that 18 of $2030(0.9 \%)$ newborn infants screened by a standard electrocardiogram with a 10-second rhythm strip had premature beats, many of which were ventricular in origin..$^{15} 16$ Twenty-four-hour recordings showed episodes of ventricular or supraventricular tachycardias in 
Table 2 Comparison of lowest and highest rates over 24 hours in age group 1 to 3 days and age group 4 to 10 days

\begin{tabular}{|c|c|c|c|c|c|c|c|c|c|c|c|c|}
\hline \multirow[b]{2}{*}{ Age (d) } & \multicolumn{4}{|c|}{$\begin{array}{l}\text { Highest rate/minute } \\
\text { (measured over } 9 \text { beats) }\end{array}$} & \multicolumn{4}{|c|}{$\begin{array}{l}\text { Lowest rate/minute } \\
\text { (measured over } 3 \text { beats) }\end{array}$} & \multicolumn{4}{|c|}{$\begin{array}{l}\text { Lowest rate/minute } \\
\text { (measured over } 9 \text { beats) }\end{array}$} \\
\hline & Min. & Max. & Mean & $S D$ & Min. & Max. & Mean & $S D$ & Min. & Max. & Mean & $S D$ \\
\hline $1-3$ & 120 & 220 & 173 & 19 & 53 & 105 & 81 & 11 & 59 & 119 & 93 & 12 \\
\hline $\begin{array}{l}\text { 4-10 } \\
P \text { value }\end{array}$ & $\begin{array}{l}140 \\
<0 \cdot 10\end{array}$ & 205 & 179 & 16 & $\begin{array}{l}36 \\
\text { Not si }\end{array}$ & $\begin{array}{l}110 \\
\text { nificant }\end{array}$ & 82 & 14 & $\begin{array}{l}42 \\
\text { Not si }\end{array}$ & $\begin{array}{l}120 \\
\text { nificant }\end{array}$ & 94 & 13 \\
\hline
\end{tabular}

Table 3 Comparison of reports on long-term electrocardiographic monitoring in the neonate

\begin{tabular}{|c|c|c|c|c|}
\hline & Southall et al. ${ }^{7}$ & Välimäki ${ }^{18}$ & Välimäki and Tarlo 10 & Morgan and Guntheroth ${ }^{17}$ \\
\hline Duration of recording $(\mathrm{hr}$ ) & 24 & 36 & 30 & 5 \\
\hline Number studied & 134 & 50 & 68 & 50 \\
\hline Age at recording (d) & $1-10$ & $1-2$ & $1-2$ & $1-7$ \\
\hline Maximum heart rate per min & 220 & 260 & 260 & 170 \\
\hline Minimum heart rate per $\min$ & 42 & 86 & 80 & 75 \\
\hline \multirow{3}{*}{$\begin{array}{l}\text { Junctional escape rhythms (\%) } \\
\text { P wave and PR interval variation } \\
\text { (\%) } \\
\text { Premature beats }(\%)\end{array}$} & 19 & 10 & 13 & 一 \\
\hline & 25 & 20 & 15 & 一 \\
\hline & 14 & 8 & 9 & 2 plus 'a few' \\
\hline
\end{tabular}

five of this latter group. Premature beats, frequent enough to be detected on standard electrocardiograms, are therefore more likely to be associated with tachyarrhythmias than occasional premature beats found only on 24-hour electrocardiographic recordings. The latter are likely to be a normal feature of the newborn heart rhythm.

In Table 3 the findings of our study are compared with those of three other reports describing longterm electrocardiographic monitoring of healthy full-term infants. ${ }^{17-19}$ The maximum and minimum heart rates found by Välimäki ${ }^{18}{ }^{19}$ are higher than those found by the direct electrocardiographic analysis method used in our study. Their technique of measuring rate was, however, similar to the automatic histogram module of our 'Oxford' analyser. We have shown that movement artefacts and large $T$ waves are often interpreted as extra QRS complexes by this automatic histogram module, thus giving spuriously high heart rates. This could explain the higher results in their study. The shorter time of recording used by Morgan and Guntheroth ${ }^{17}$ may explain the absence of junctional escape rhythms or the absence of $P$ wave and PR interval variation in their study.

Twenty-four-hour recordings have shown that electrocardiographic rhythm patterns previously described as representing disorders of sinus node function occur in the healthy neonate. We have also found differences between the values of highest and lowest heart rates measured in this study and those previously reported on long-term electrocardiographic recordings. The interpretation of heart rhythm and rate in clinical situations must take normal data into consideration.

Dr Southall has a grant from the Board of Governors of the Brompton Hospital, and Jean Richards from the Foundation for the Study of Infant Death. The project was supported by grants from the British Heart Foundation and the Wessex Regional Health Authority. Generous donations were also given by the League of Friends of Dorchester and Weymouth Hospitals, the Weymouth Round Table, Weymouth Lions, and Weymouth Auxiliary League of the Licensed Trade.

The Oxford Instrument Company gave invaluable support to this work.

\section{References}

${ }^{1}$ Schamroth L, Dove E. The Wenckebach phenomenon in sino-atrial block. Br Heart f 1966; 28: 350-8.

${ }^{2}$ Urbach J R, Phuvichit B, Zweizig H, et al. Instantaneous heart rate patterns in newborn infants. $A m \mathcal{F}$ Obstet Gynecol 1965; 93: 965-74.

${ }^{3}$ Siegel S. Non parametric statistics. New York: McGrawHill, 1956: 47-52.

${ }^{4}$ Liebman J. Electrocardiography. In: Moss AJ, Adams $\mathrm{FH}$, eds. Electrocardiography in heart disease in infants, children and adolescents. Baltimore: William \& Wilkins, 1968: 183-99.

${ }^{5}$ Vallbona C, Desmond MM, Rudolph AJ, et al. Cardiodynamic studies in the newborn. II. Regulation of the heart rate. Biol Neonate 1963; 5: 159-99. 
${ }^{6}$ Lipton EL, Steinschneider A, Richmond JB. Autonomic function in the neonate. VIII. Cardiopulmonary observations. Pediatrics 1964; 33: 212-5.

7Southall DP, Richards J, Brown DJ, Johnston PGB, de Swiet M, Shinebourne EA. Twenty-four hour tape recordings of ECG and respiration in the newborn infant with findings related to sudden death and unexplained brain damage in infancy. Arch Dis Child 1980; 55: 7-16.

${ }^{8}$ Southall DP, Johnston F, Richards JM, Shinebourne EA, Johnston PGB. Study of heart rate and rhythm in normal schoolchildren (abstract). Br Heart $\mathcal{F} 1979 ; 42$ : 234.

${ }^{9}$ Scott O, Macartney FJ, Deverall PB. Sick sinus syndrome in children. Arch Dis Child 1976; 51 : 100-5.

${ }^{10}$ Yabek SM, Swensson RE, Jarmakani JM. Electrocardiographic recognition of sinus node dysfunction in children and young adults. Circulation 1977; 56: 235-9.

${ }^{11}$ Greenwood RD, Rosenthal A, Sloss LJ, LaCorte M, Nadas A. Sick sinus syndrome after surgery for congenital heart disease. Circulation 1975; 52: 208-13.

${ }^{12}$ El-Said GM, Gillette PC, Cooky DA, Mullins CE, McNamara DG. Protection of the sinus node in Mustard's operation. Circulation 1976; 53: 788-91.
${ }^{13}$ Saalouke MG, Rios J, Perry LW, Shapiro SR, Scott LP. Electrophysiologic studies after Mustard's operation for d-transposition of the great vessels. Am $\mathcal{F}$ Cardiol 1978; 41 : 1104-9.

${ }^{14}$ Onat $A$, Domaniç $N$, Onat T. Sick sinus syndrome in and infant. Eur $\mathcal{f}$ Cardiol 1974; 2: 79-83.

${ }^{15}$ Southall DP, Vulliamy DG, Davies J, Anderson RH, Shinebourne EA, Johnson AM. A new look at the neonatal electrocardiogram. $\mathrm{Br}$ Med f 1976; 2: 615-8.

${ }^{16}$ Southall DP, Orrell MJ, Talbot JF, et al. Study of cardiac arrhythmias and other forms of conduction abnormality in newborn infants. $\mathrm{Br} M e d \mathcal{F} 1977 ; 2$ : 597-9.

${ }^{17}$ Morgan BC, Guntheroth WG. Cardiac arrhythmias in normal newborn infants. F Pediatr 1965; 67: 1199-202.

${ }^{18}$ Välimäki I. Tape recordings of the electrocardiogram in newborn infants. Section II Long-term ECG tape recordings of newborn infants. Acta Paediatr Scand [Suppl] 1969; 199: 1-75.

${ }^{19}$ Välimäki I., Tarlo PA. Heart rate pattern and apnea in newborn infants. Am $\mathcal{F}$ Obstet Gynecol 1971; 110: 343-9.

Requests for reprints to Dr D P Southall, Cardiothoracic Institute, Fulham Road, London SW3 6HP. 